\title{
Status of Salmon in a Changing Environment: A Perspective from Alaska
}

\author{
Andrew R. Munro' ${ }^{1}$ Richard E. Brenner ${ }^{2}$, and William D. Templin ${ }^{1}$ \\ ${ }^{I}$ Alaska Department of Fish and Game, Division of Commercial Fisheries, 333 Raspberry Road, Anchorage, Alaska \\ 99518-1599, USA \\ ${ }^{2}$ Alaska Department of Fish and Game, Division of Commercial Fisheries, P.O. Box 115526, Juneau, Alaska 99811 - \\ 5526, USA
}

Keywords: Pacific salmon, stock status, Eastern North Pacific, abundance

Salmon are an important natural, economic, and cultural resource for many people across the northern Pacific Rim, including all five North Pacific Anadromous Fish Commission (NPAFC) member nations. Monitoring and understanding the status of salmon stocks is critical to the management and conservation of this shared resource, especially within the context of a changing and increasingly variable environment that these stocks interact in (e.g., ocean warming and ocean acidification). It is unclear what the future holds for our salmon populations, but we need to think about, and prepare for, the inevitable changes.
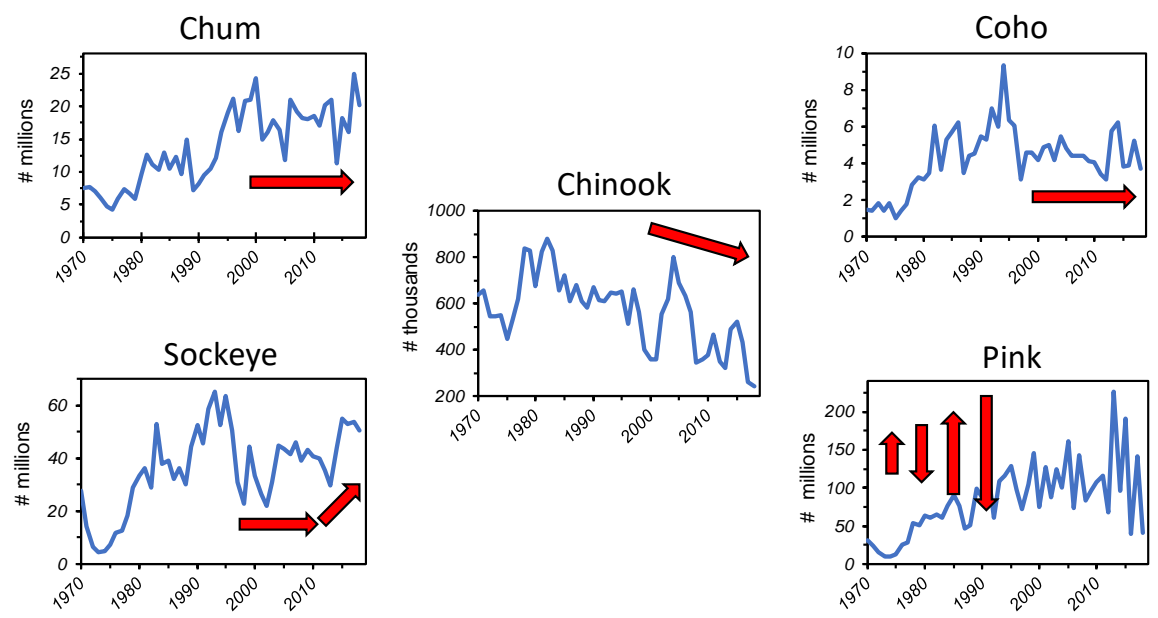

Fig. 1. Catch of chum, coho, Chinook, sockeye, and pink salmon in Alaska salmon fisheries from 1970 to 2018 (from Brenner et al. 2019). The red arrows indicate general trends in recent years.
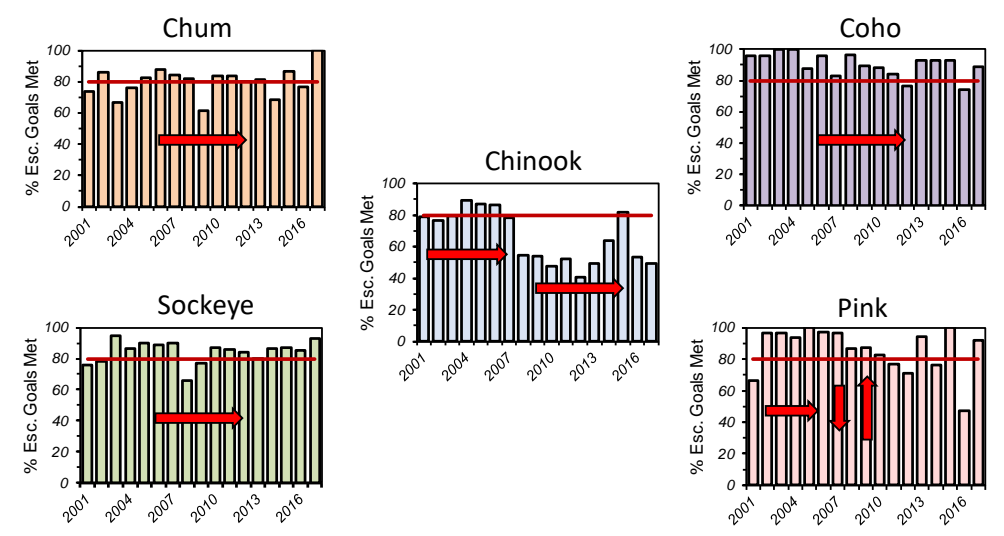

Fig. 2. Percentage of escapement goals met for chum, coho, Chinook, sockeye, and pink salmon across Alaska from 2001 to 2017 (from Munro 2018). The red horizontal line at $80 \%$ is a benchmark target used to evaluate the performance of the Alaska Department of Fish and Game in meeting escapement goals. The red arrows indicate general trends in recent years.

Across Alaska, trends in commercial harvest and the ability to meet escapement goals amongst the five native Pacific salmon species have varied over time (Figs. 1, 2). For chum and coho salmon, harvest and meeting escapement goals has been stable. Sockeye salmon harvest has been variable through time, with a recent increase being driven by large runs to Bristol Bay, yet escapement goals are consistently met. Variability in the abundance of pink salmon runs between even and odd-year broodlines is increasing as reflected in both commercial harvest and the ability to meet escapement goals. Chinook salmon runs in Alaska have declined in the last decade, leading to restrictions throughout Alaska for commercial, sport and subsistence fisheries. Similar trends have been observed 
elsewhere (Irvine et al. 2018; Klovach et al. 2018). Despite these restrictions, meeting escapement goals has been challenging and has led to listing of several Alaskan stocks as "stocks of concern" (Table 18 in Munro 2018).

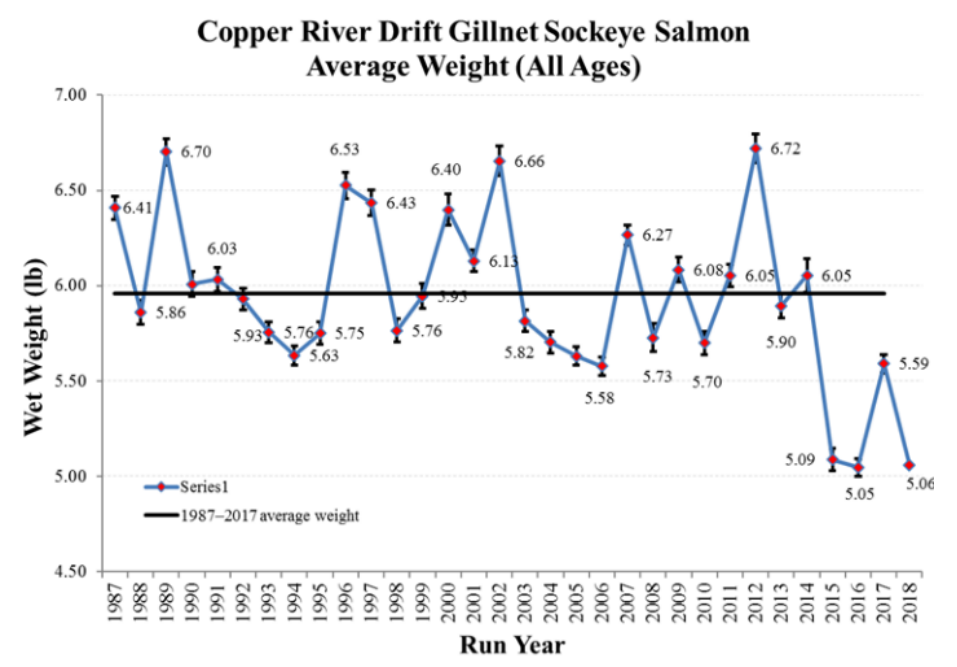

Fig. 3. Average annual weights of Copper River sockeye salmon caught in the commercial drift gillnet fishery from 1987 to 2018 (S. Haught, ADF\&G, unpublished data).

In addition to these broad-scale changes, salmon returns throughout Alaska have displayed changes in several life history characteristics such as size, age at return, and timing. These changes, however, have not manifested themselves uniformly within or among species nor are they unique to Alaska. Studies have documented declining age at maturity and size at age in Chinook salmon (Lewis et al. 2015) and recent declines in the weight of sockeye salmon relative to long-term averages (Fig. 3). There are also patterns emerging at the basin scale. For example, recent Bristol Bay sockeye runs have been good, with 2018 being the largest run on record, whereas returns of sockeye salmon to rivers that enter the Gulf of Alaska were generally poor that same year (Brenner et al. 2018). Similarly, recent even-year pink salmon returns have been particularly poor for Gulf of Alaska stocks, but returns of pink salmon in western Alaska have increased (Fig. 4).

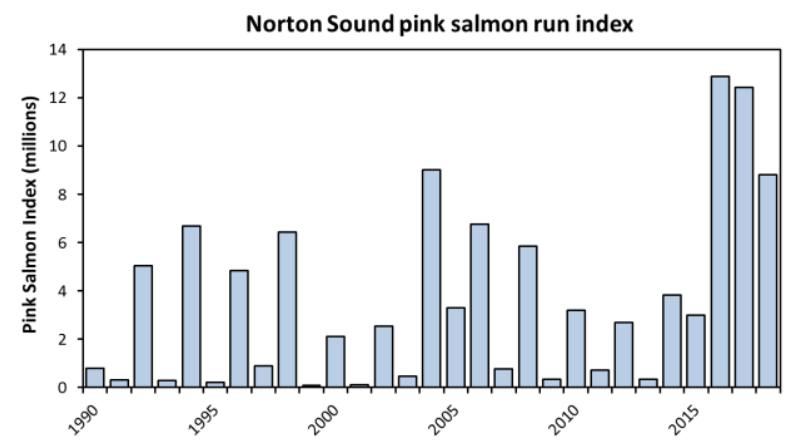

Fig. 4. Index of Norton Sound pink salmon run from 19902018 (S. Garcia, ADF\&G, unpublished data).

The mechanisms driving these observed patterns are not well understood, and hypotheses are currently being debated, examined, and tested. For example, it is hypothesized that some of these changes, particularly in stocks from the Gulf of Alaska, may be related to the anomalous pool of warm water prevalent in the northeast Pacific Ocean from 2014 to 2017. Species interactions and large-scale environmental patterns such as El Nino events and the Pacific Decadal Oscillation may also explain some of the recent observations and trends. However, the challenge is to gain a better understanding of the underlying mechanisms as well as the ecological and environmental drivers of salmon populations, which can best be met by sound hypothesis-driven science. Admittedly, hypothesis testing in the traditional sense is difficult (or even impossible) in complex ecosystems such as the North Pacific Ocean, but sound science involves an iterative process of proposing plausible mechanisms and representing them in models, then testing the models and their assumptions with data, followed by refining our concept of the mechanism. Performing sound science with rigorous methods will not only help scientists better understand salmon populations but also provide information that is useful for fisheries management in the face of a rapidly changing environment. The monitoring of southeast Alaska Chinook salmon stocks which, like elsewhere, have declined significantly in recent years (Fig. 5a), provides a good example of this approach. It was hypothesized that these declines might be related to poor marine survival. Estimates of freshwater and marine survival based on juvenile coded-wire tagging studies indicate that marine survival for brood years since 2001 have declined to below 
average despite above-average freshwater survival for some of the same brood years (Fig. 5b). This information has been instrumental in developing management strategies that resulted in heavily restricted fishing for southeast Alaska Chinook salmon for the past two years.
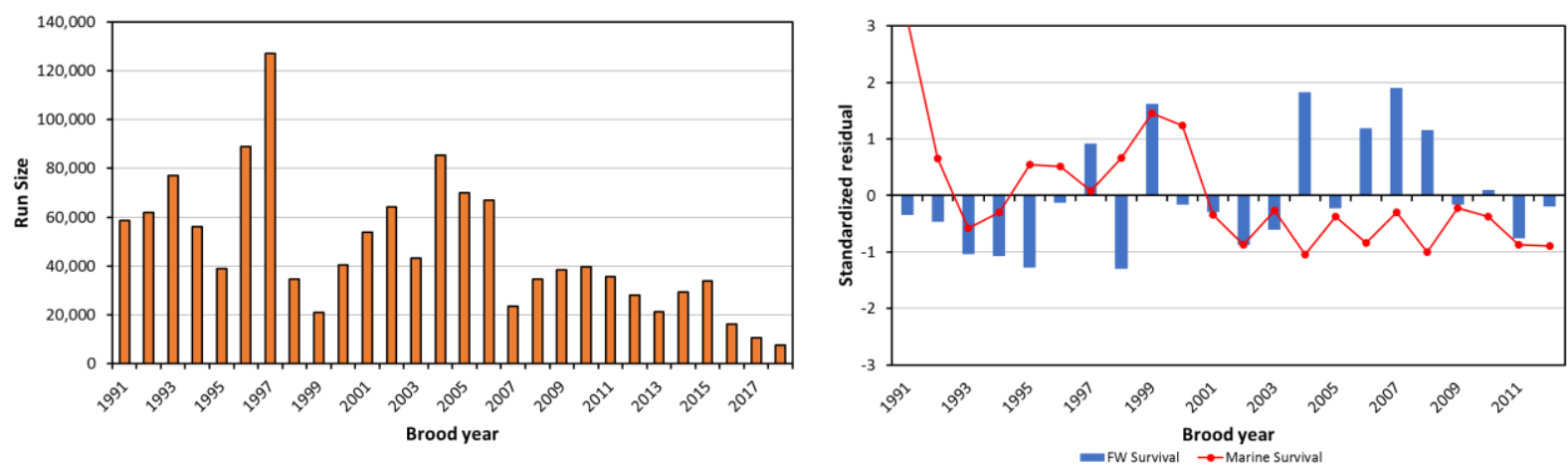

Fig. 5. Taku River Chinook salmon a) (on the left) run size from 1991 to 2017 and b) (on the right) standardized residuals of estimated freshwater and marine survival for brood years 1991 through 2012 (CTC 2019).

Although there are many indications that salmon production in the ocean is changing, the challenges that all nations with salmon resources face are to: 1) take careful and consistent measurements of the ecosystem, 2) investigate drivers of community and ecosystem changes, 3 ) consider what these changes may mean to the present and future status of salmon stocks, and 4) predict how various stocks may respond to the changing "pasture" they all share in the North Pacific Ocean. Ultimately, we must thoughtfully and collaboratively address these challenges if we are to adapt our efforts to effectively manage salmon stocks in a changing environment. The challenge can best be met with using scientific methods. To do so, we must pose crucial questions and match them with well-designed studies and analyses that recognize the limitations in quality and quantity of current data and identify future needs. Through the use of sound science, we will gain a better understanding of the drivers and mechanisms affecting salmon populations, which can then be developed into useful tools and resilient strategies to be used with confidence by managers and policy makers in increasingly uncertain times. With a well provisioned toolbox, managers and stakeholders will be able to make informed, educated decisions that will ensure the use of salmon as a sustainable resource.

\section{REFERENCES}

Brenner, R.E., A.R. Munro, and S.J. Larsen (Editors). 2019. Run forecasts and harvest projections for 2019 Alaska salmon fisheries and review of the 2018 season. Alaska Department of Fish and Game, Special Publication No. 19-07, Anchorage. http://www.adfg.alaska.gov/FedAidPDFs/SP19-07.pdf.

CTC (Chinook Technical Committee). 2019. Annual report of catch and escapement for 2018. Pacific Salmon Commission, Report TCCHINOOK (19)-1. Vancouver, BC.

Irvine, J.R., A.R. Munro, W. Templin, M. Thiess, S. Grant, and E. Neatherlin. 2018. Status Overview for Pacific Salmon Populations in the Eastern North Pacific Ocean. N. Pac. Anadr. Fish Comm. Tech. Rep. 11: 1-7. (Available at https://npafc.org)

Klovach, N.V., O.S. Temnykh, V.A. Shevlyakov, E.A. Shevlyakov, A.F. Bugaev, V.I. Ostrovskiy, A.M. Kaev, and V.V. Volobuev. 2018. Current Stock Assessment of Pacific Salmon in the Far East of Russia. N. Pac. Anadr. Fish Comm. Tech. Rep. 11: 12-16. (Available at https://npafc.org)

Lewis B., W.S. Grant, R.E. Brenner, and T. Hamazaki. 2015. Changes in Size and Age of Chinook Salmon Oncorhynchus tshawytscha Returning to Alaska. PLoS One. 10(6): e0130184. doi.org/10.1371/journal.pone.0130184.

Munro, A.R. 2018. Summary of Pacific salmon escapement goals in Alaska with a review of escapements from 2009 to 2017. Alaska Department of Fish and Game, Fishery Manuscript Series No. 18-04, Anchorage. http://www.adfg.alaska.gov/FedAidPDFs/FMS18-04.pdf. 